\title{
MODIFIED APPROACH TO SPHINCTEROTOMY IN SPINAL CORD INJURY PATIENTS
}

\author{
Indications, Technique and Results in 32 Patients
}

\author{
By INDER PerKash, M.D., M.S., F.R.C.S., F.A.C.S. \\ Spinal Cord Injury Centre, VA Hospital, Palo Alto, California Department of Surgery
}

(Urology), Stanford University

EMmetr AND DunN (1946) had reasoned that the external sphincter is the most important single factor in the control of micturition. Several reports in the recent past have emphasised that the primary and most important cause of vesical outlet obstruction in spinal cord injury patients is the external sphincter (Semens and Bunts, 196I; Currie et al., 1970). It has also been recommended that high and complete quadriplegic patients should undergo transurethral external sphincterotomy as soon as their lesions are established and complete (O'Flynn, 1972). Essential technique employed has been knife-electrode posterolateral incisions in the urethra starting at the level of verumontanum and going down to the bulbous urethra. Transurethral resection of the vesical neck seems to be the treatment of choice in paraplegic patients and external sphincterotomy is indicated when micturition is unsatisfactory after adequate transurethral resection. On the other hand, Ascoli (1967), on the basis of radiological studies, pointed out that transurethral resection was not indicated if the posterior urethra showed dilatation in such patients. It has also been suggested that due to the spastic sphincter, bladder outlet may as well show hypertrophy of the bladder neck as a part of general hypertrophy of detrusor muscle (O'Flynn, 1972). Transurethral resection of the bladder neck is thus needed in such patients after failure following sphincterotomy.

The satisfactory results following first transurethral surgery have only ranged between 30 and 70 per cent (Rossier and Ott, 1974; Ross, Gibbon and Damanski, 1963; Bors and Commarr, 1954). Results improved considerably after multiple operations (Rossier and Ott, 1974). An attempt has been made to understand and treat voiding dysfunction in I50 spinal cord injury patients. This is being presented elsewhere (Perkash). Present study is an analysis of various factors responsible for inadequate voiding in 32 such patients where a slightly modified extended transurethral sphincterotomy was performed. Indications, technique and results are being presented. Overall satisfactory results were obtained in about 90 per cent patients following first surgery.

\section{Methods and Materials}

There were 32 patients with clinically complete lesions out of a series of about over 250 patients treated at the VA Hospital, Palo Alto, and the VA Hospital, Houston. Table I shows the level of injury.

They were all male patients and they ranged between the age group of $2 \mathrm{I}$ to $8 \mathrm{I}$. There were seven patients over the age of 50 years. Table II shows the period 
TABLE I

Level of injury

I. Paraplegia

$\begin{array}{ll}\text { a. High lesions }\left(\mathrm{T}_{3-4}\right) & 9 \\ \text { b. Low lesions } & 8\end{array}$

I7 patients

2. Cauda equina ( $T_{12}$ and below)

3. Quadriplegia

9
6

32 patients

Total

(All patients had complete clinical lesions.)

TABLE II

Period after injury transurethral surgery was performed

$\begin{array}{ccccc}\text { I2-25 weeks } & \text { I-2 years } & 3-5 \text { years } & 6-9 \text { years } & \text { I4-25 years } \\ 7 & 8 & 4 & 6 & 7\end{array}$

\section{TABLE III}

Presenting problems in the present series

I. Prolonged I.C.P. over 20 weeks (one 13 weeks post-injury)

Patients

2. Failed I.C.P. elsewhere (indw. cath. 7 months to

$\begin{array}{cc}4 \text { years) ( } 3 \text { pts. with severe dysreflexia) } & \text { Io } \\ \text { 3. High residuals, repeated infections and difficult voiding } & \text { Io }\end{array}$

I2

after spinal cord injury when transurethral surgery was performed. Presenting problems in this group of patients are shown in Table III.

Patients on intermittent catheterisation programme with inadequate spontaneous voiding, about 8-Io weeks post injuries, were studied; combined cysto-metrographic E.M.G. pelvic floor and voiding cysto-urethrographic studies were performed to find out derusor activity, status of bladder neck and posterior urethra and detrusor-sphincter dyssynergia (fig. I, A). In 26 patients carbon dioxide cystometrogram and urethral pressure studies (fig. 2, A) were carried out before and after surgery. ${ }^{1}$ Patients with Foley indwelling catheter and failed Intermittent Catheterisation Programme elsewhere were decatheterised and placed on intermittent catheterisation before they were studied for their dysfunctional bladder

${ }^{1}$ Heyer-Schulte $\mathrm{CO}_{2}$ Urinary Analyser (Catalogue No. 470-1000) was employed. Foley catheter \# $\mathrm{I} 2$ was inserted aseptically, C.M.G. was carried out by using $90 \mathrm{cc}$. $\mathrm{CO}_{2}$ per minute and the paper speed employed was $60 \mathrm{~mm} /$ minute. Urethral pressure profile was recorded by first distending the foley bag against the bladder neck and by marking the catheter near the external meatus and then by withdrawing deflated catheter at 2.5 and 3.5 $\mathrm{cm}$. out of the urethra. $\mathrm{CO}_{2}$ was run $60 \mathrm{cc}$ per minute for urethral pressure studies. End point was when the pressure dropped and there was leakage of $\mathrm{CO}_{2}$ around the catheter. 
G.G.

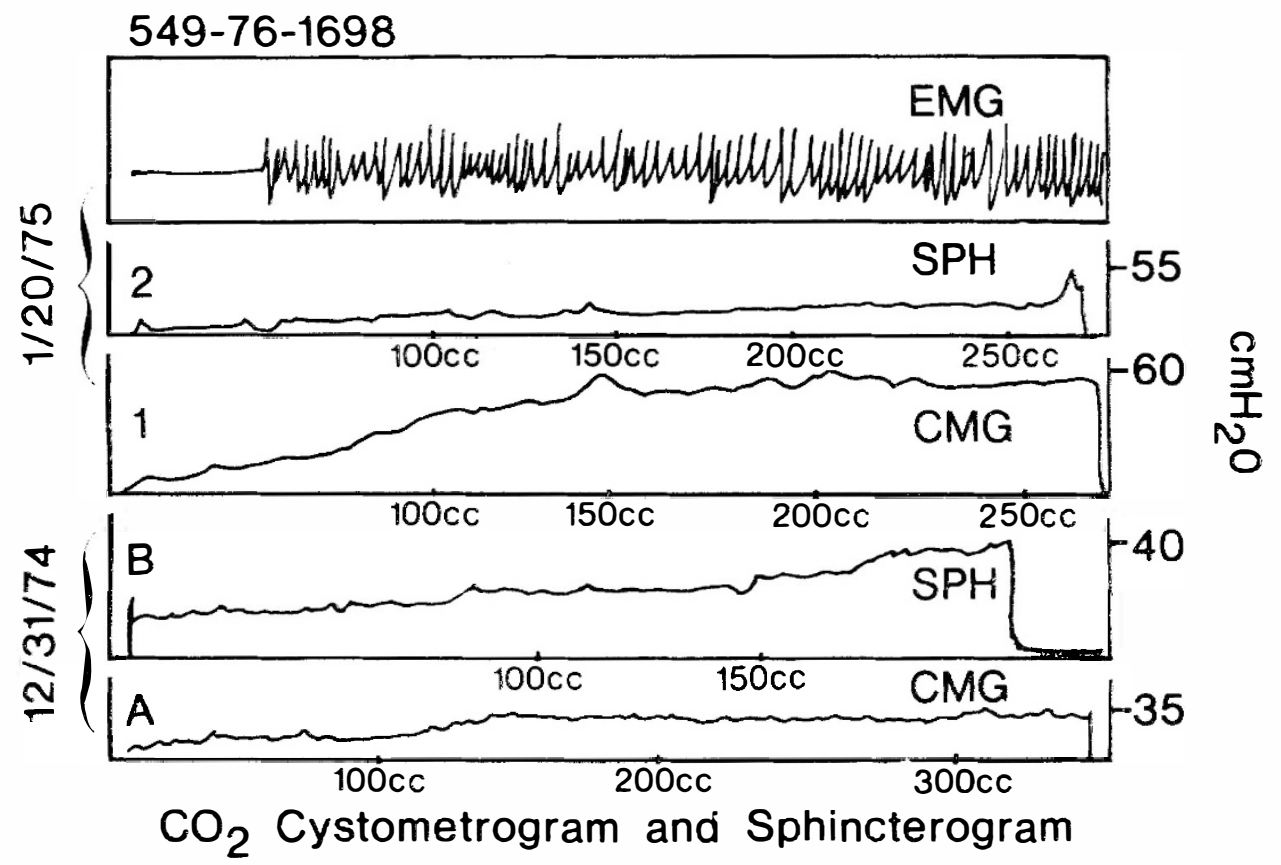

FIG. IA

G. G., 25 years old, C5-6 quad. Failed int. cath. Indwelling cath. for $2_{2}^{1}$ years. Severe autonomic dysreflexia. Following sphincterotomy is December 1974, indwelling cath. removed. Kept on intermittent catheterization programme until I4 January 1975. Serial voiding urethrographic studies show functioning bladder neck on 20 January 1975.
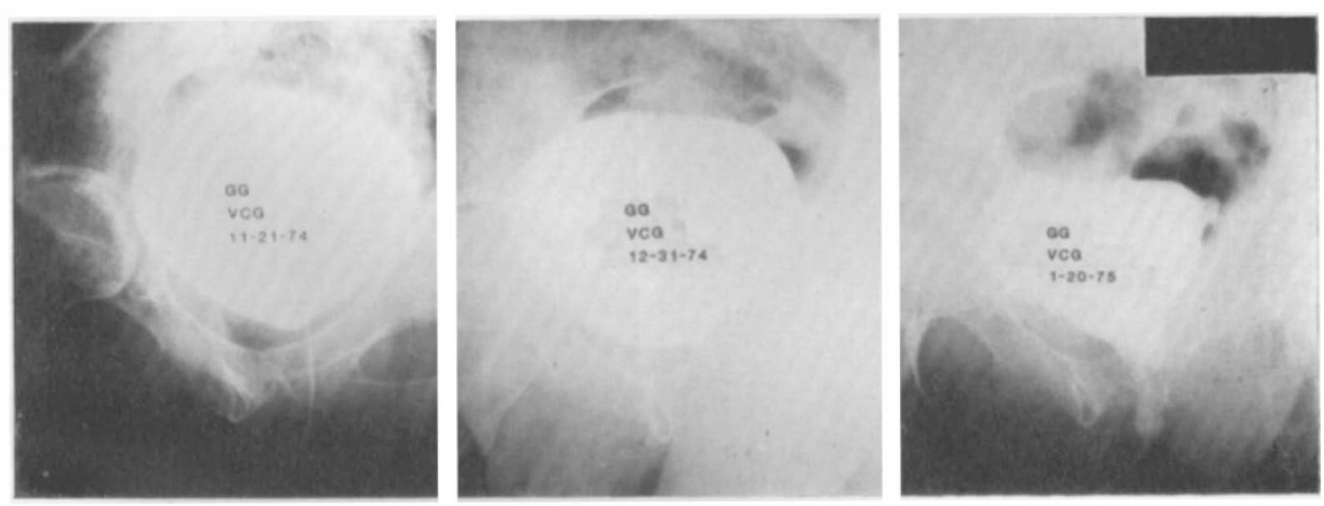

FIG. IB

Combined $\mathrm{CO}_{2}$ C.M.G., E.M.G. and intra-urethral pressure studies (sph.) before and after sphincterotomy show detrusor-sphincter dyssynergia. 


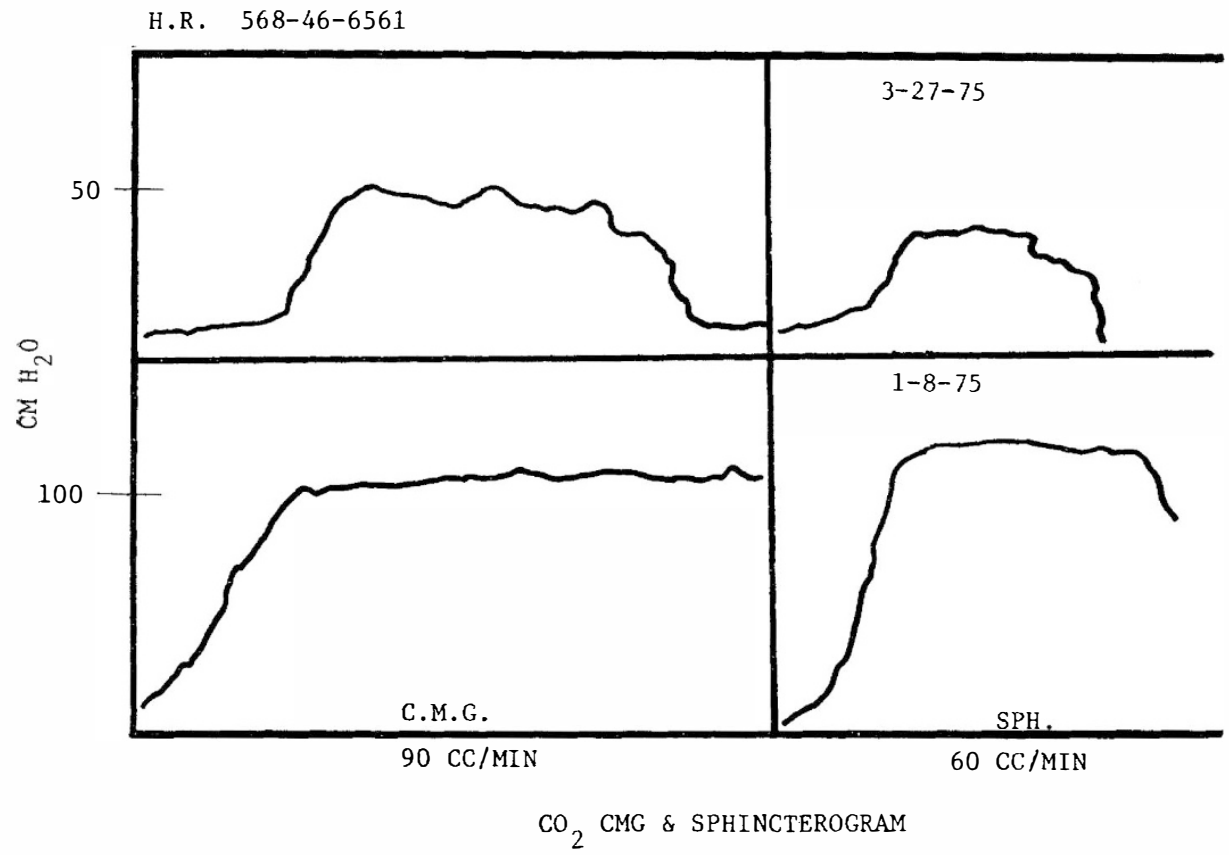

FIG. 2A

H. R., 4I years old, $\mathrm{T}_{3}$ lesion. Pre- and post-operative $\left(\mathrm{CO}_{2}\right)$ C.M.G. and sphincterogram show about 50 to $60 \mathrm{~cm}$. pressure drop following surgery. Pre-op studies on 8 January 1975 show sustained high pressure C.M.G. (about $100 \mathrm{~cm} . \mathrm{H}_{2} \mathrm{O}$ and sphincter pressure over $100 \mathrm{~cm}$. of $\mathrm{H}_{2} \mathrm{O}$ ).
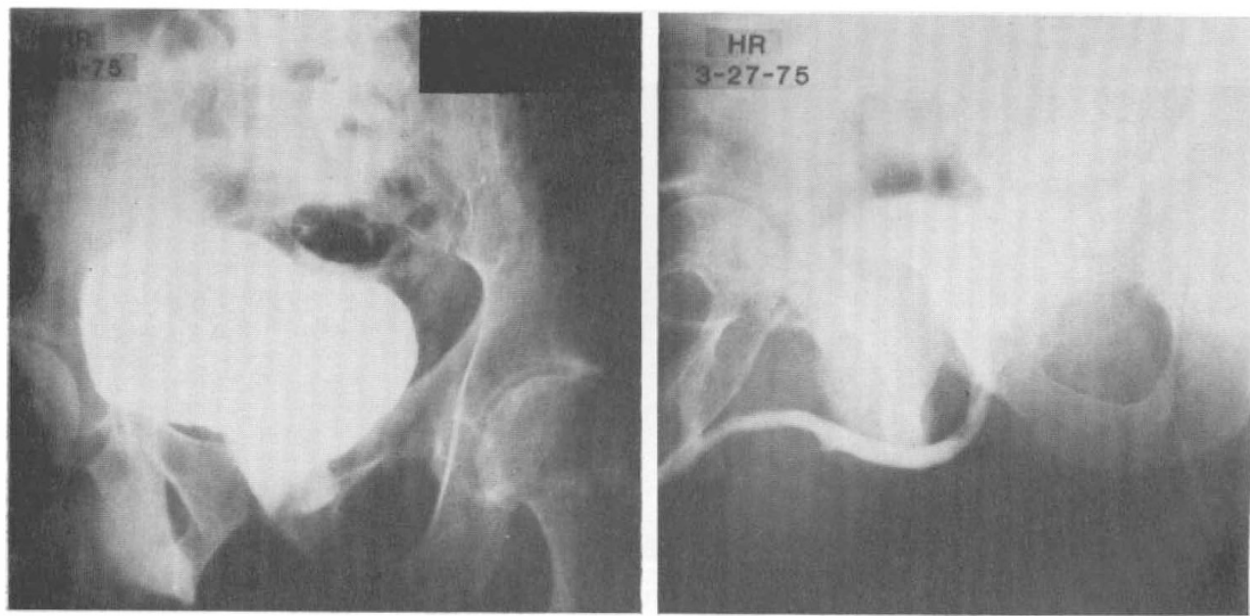

FIG. 2B

Voiding studies show widely open bladder neck from previous T.U.R.P. and no voiding, post-sphincterotomy studies on 27 March 1975 shows well patent posterior urethra and adequate voiding. 


\section{TABLE IV}

Indications for sphincterotomy

I. Prolonged I.C.P. (over 20 weeks) in complete lesions.

2. Vesico-ureteral reflux in complete transections.

3. High residuals and severe autonomic dysreflexia.

4. Upper tract changes with sustained high intravesical pressure and spastic sphincter.

5. Overdistended (atonic) or areflexic bladder with inability to open bladder neck on voiding cystourethrographic studies. (At least 3 months postinjury.)

6. Repeated urinary tract infections with high residuals and difficulty to empty bladder.

\section{TABLE V}

\section{Type of surgery}
A. 3, 9 o'clock up to veru. and 12 o'clock $1 \cdot 5 \mathrm{~cm}$.- $2 \cdot 0 \mathrm{~cm}$. distal to veru.
B. $3,9,12$ o'clock sph. (about $1 \cdot 5$ to $2 \cdot 0 \mathrm{~cm}$ distal to veru.)
C. I.T.U.R.P. (3-I8 G) and 3-9 o'clock incision
II. T.U.R.P. and 12 o'clock incision

\section{Patients}
5

and bladder-neck problems. The urinary tract infections were treated with adequate antibiotic therapy. Indications for surgery are shown in Table IV.

\section{Operative Technique}

Most of the patients were operated under spinal or low caudal anesthesia. Cysto-urethroscopic examination of bladder neck and posterior urethra was first carried out; state of posterior urethra, bulging lateral lobes of prostate if any, and the elasticity of the bladder neck were noticed. Type of surgery performed slightly varied with the urodynamic findings and cysto-urethroscopic examination at the time of surgery. A.C.M.I. resectoscope was employed and Collings knife was used for myotomy incisions at the bladder neck and in posterior urethra. Lateral lobes falling within the urethra were resected by using a diathermy loop. Collings knife incisions at three and nine o'clock on the first five patients were employed from bladder neck to verumontanum and also a 12 o'clock incision in front of verumontanum to about $\mathrm{I} \cdot 5 \mathrm{~cm}$. distal into the urethra. The results were 'not very satisfactory' in two out of five patients, therefore, in subsequent patients lateral incisions were made from bladder neck to about $\mathrm{I} \cdot 5-2 \cdot 0 \mathrm{~cm}$. distal to verumontanum just short of cutting bulbous urethra. Type of surgery performed is shown in Table V. A.C.M.I. Collings knife is smaller than Storz and it is preferred in making gentle sweeps and cuttings $2-3 \mathrm{~mm}$. depths at a time until 
TABLE VI

Significant pathological findings in 32 patients

Radiological Patients

I. Inability to open bladder neck adequately on attempted voiding

2. Vesico-urethral reflux

3. Gross hydronephrosis

20

IO

Cystometric and E.M.G.

4. Areflexic bladder

5. High intravesical pressures (over $75 \mathrm{cmH}_{2} \mathrm{O}$ )

6. Detrusor-sphincter dyssynergy

a. With marked spasticity

b. With minimal spasticity

Cystoscopic

7. Urethral and bladder neck fibrotic changes

8. Coarse trabeculations and cellules in bladder

sudden gaping of the incision was noticed with smooth underlying urethral wall. At least two, sometimes three, sweeps were required to obtain adequate sphincterotomy. Bleeding has been minimal and it was controlled with electro-coagulation. In two patients where the indwelling catheter had recently been removed, urethra was friable and Collings knife incisions could be made by electro-coagulation with minimal use of cutting diathermy. A Foley indwelling catheter $\# 22$ or $24 \mathrm{~F}$ was usually left for about a week to ten days. No significant secondary haemorrhage was encountered in any patient. Following the removal of the indwelling catheter, patients were placed on intermittent catheterisation to study their spontaneous voiding and residual urine. In two acute paraplegics and one quadriplegic patient (fig. I, B) intermittent catheterisation was required for about three to five weeks before they developed adequate spontaneous voiding and residuals were lower than $100 \mathrm{cc}$. when intermittent catheterisation was stopped. All patients were followed about three weeks after discharge and then every two to three months. Maximum follow-up has been about three years and minimum about six months.

\section{Results}

Significant pathological findings on radiological, C.M.G., E.M.G., and voiding cysto-urethrographic studies are shown in Table VI. There were 20 patients who could not open the bladder neck adequately at attempted voiding during cystourethrographic studies. This was noticed in all the patients with areflexic bladder (fig. 3) and also in patients who had urethral and bladder-neck fibrotic changes on cystoscopic examination. Two patients with severe detrusor-sphincter dyssynergia (fig. I, B) also did not open the bladder neck at attempted voiding. There were ten patients who had vesico-ureteral reflux; all of them had higher intravesicular pressure on $\mathrm{CO}_{2}$ C.M.G. which ranged between $75 \mathrm{~cm}$. of $\mathrm{H}_{2} \mathrm{O}$ to about $150 \mathrm{~cm}$. of $\mathrm{H}_{2} \mathrm{O}$. Urethral pressures were invariably higher and sustained than $75 \mathrm{~cm}$. of $\mathrm{H}_{2} \mathrm{O}$ (see fig. 2, A). Detrusor-sphincter dyssynergia was noticed 

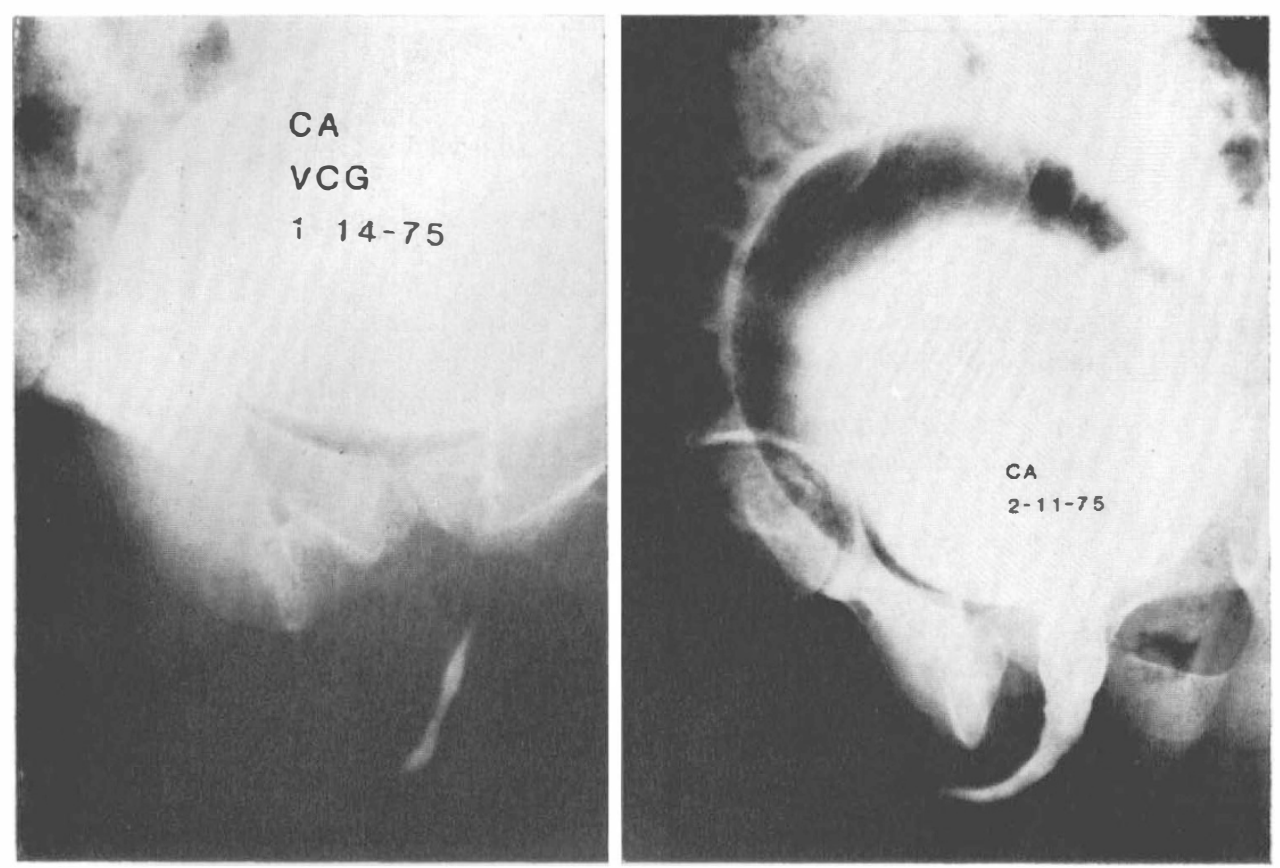

FIG. 3

C. A., 2 I years old, acute $T_{12}-L_{1}$ lesion. Failed intermittent catheterisation for five months with no spontaneous voiding. Voiding cyst. ureth. on I4 January 1975 shows big bladder, inadequately opened bladder neck, spastic pelvic floor. About two weeks post-sph. voiding studies show well opened bladder neck and posterior urethra with adequate voiding.

in eight patients; two out of eight patients were low paraplegics and cauda equina lesions with minimal spasticity. Three such patients needed intermittent catheterisation for a few days to three weeks post sphincterotomy, before they had adequate spontaneous voiding (fig. I, B). Table VII (A) and (B) show results of surgery. Satisfactory results were obtained in 29 out of 32 patients (see figs. 4, A, 4, B, and 4, C).

After removal of catheter following surgery, patients were taught to empty their bladder every two to three hours on a tilt bed and wheelchair; this was particularly necessary in cauda equina lesions and in patients with areflexic overdistended bladder. There was significant radiological improvement within four to six weeks post surgery (figs. 5, A, 5, B, and 5, C). Vesico-ureteral reflux almost disappeared in all but two patients. Initial residuals varied from less than $50 \mathrm{cc}$. to about $150 \mathrm{cc}$. Some of them could virtually eliminate all the urine after gentle crede-valsalva. There was an average of about $40 \mathrm{~cm}$. (range $15-100 \mathrm{~cm}$.) pressure drop on $\left(\mathrm{CO}_{2}\right)$ C.M.G., and about $25 \mathrm{~cm}$. (range $15-80 \mathrm{~cm}$.) pressure drop in the intra-urethral pressure following sphincterotomy. In two patients repeat sphincterotomy was done elsewhere and one patient is being considered for surgery again. Both the patients were two out of five patients where Collings knife incisions were made only at bladder neck and were inadequate. All three patients with 'not very 


\section{TABLE VII}

(A) Satisfactory results $=29 / 32$ patients

I. Easy voiding and symptomatic relief of dysreflexic symptoms.

2. Residual urine (I.C.P. usually less then $150 \mathrm{cc}$.).

3. Sex life maintained.

4. Uninfected urine; 90 per cent of the time in $18 / 32$ patients and over 50 per cent of the time in II/32 patients.

5. Voiding on $\mathrm{CO}_{2}$ C.M.G. (at less than $60 \mathrm{~cm}$. of water pressure).

6. Significant radiological improvement.

(B) Less than satisfactory results $=3 / 32$ patients

I. High residuals over $150 \mathrm{cc}$.

2. Infected urine more than 50 per cent of the time.

satisfactory' results have areflexic, overdistended bladder and did not void even a few ml. spontaneously prior to surgery.

\section{Discussion}

Inadequate voiding in spinal cord injury patients could be due to several factors as has been shown in the present series. There is no doubt that spastic external sphincter does play an important role in producing outlet obstruction; a fixed scarred internal ring (in about 30 per cent patients in the present series), areflexic bladder ( 19 per cent incidence in the present series) and detrusorsphincter dyssynergia ( 25 per cent incidence) with and without generalised spasticity in the lower extremities need careful considerations at the time of bladder-neck surgery. Patients in age groups over 50 years may have a small prostatic adenoma which could also contribute to the bladder-neck problems. Traditional sphincterotomy where diathermy incisions are made around verumontanum and carried down the membranous urethra to the bulb do not take into consideration the state of bladder neck.

Varying results of 35 to 70 per cent success following transurethral sphincterotomy have been reported. In the present series, knife electrode incisions were started at bladder-neck margin and were carried down to membranous urethra. Overall, 90 per cent satisfactory results were recorded. Melament (I972) observed scarring and fixed bladder neck in patients who had undergone T.U.R., and he made extensive use of knife electrode from bladder neck to the bulbous urethra in such patients. Some of the failures in his series were due to inadequate resection of prostatic tissue at the level of verumontanum. In some of our patients with minimal prostatic adenoma, lateral lobes became prominent and appeared bulging after Collings knife incisions were made at three and nine o'clock positions. They were resected with loop diathermy and then knife electrode incisions were made from bladder neck to just short of bulbous urethra. It is not recommended to cut bulb as it does lead to excessive haemorrhage at the time of surgery and also 


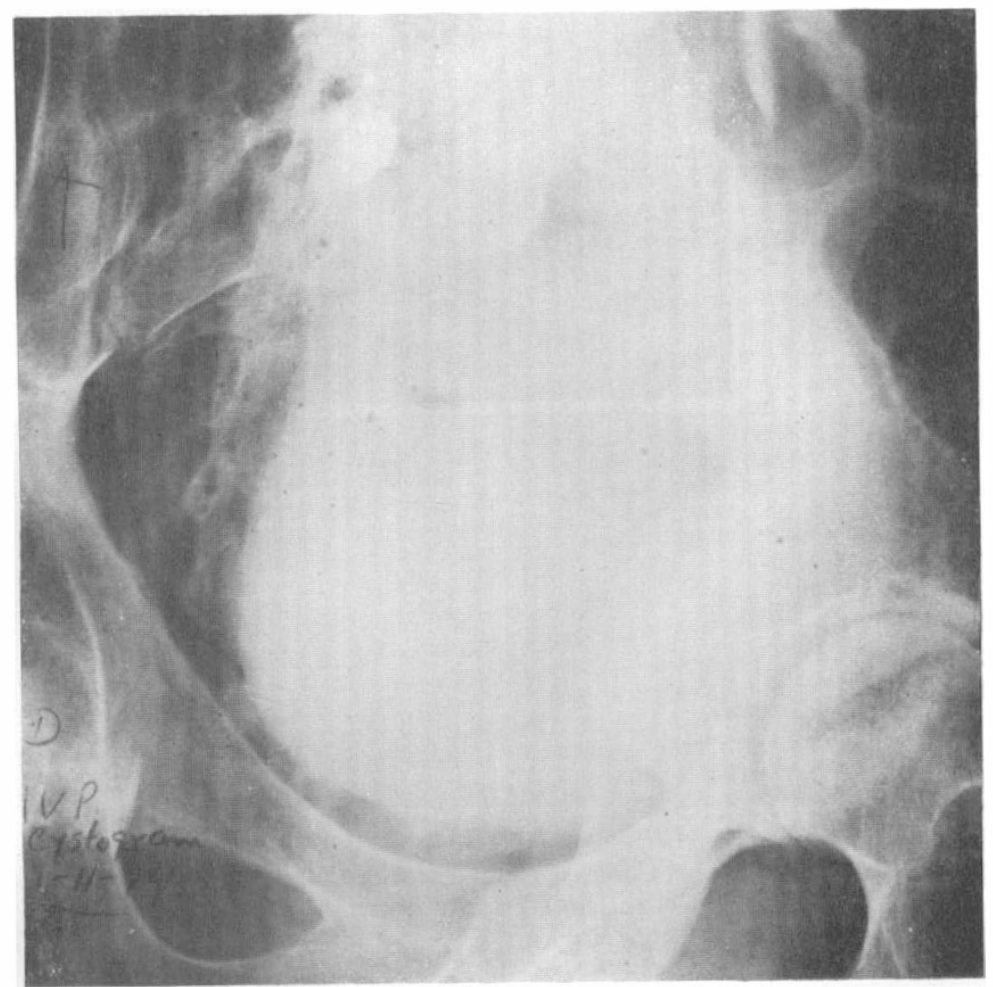

FIG. 4A

R. D., 25 years old, C5-6 quad. Voiding cyst. ureth. shows big bladder and inability to open bladder neck and urethra and autonomic dysreflexia.

possibly impotence later on. In the present series there was no change in sexuality in these patients following surgery. I believe this is due to utmost care being taken at the time of surgery to avoid cutting or damaging bulbous urethra. All patients maintained reasonable degree of continence (fig. 4, C) which could also be attributed to intact bulbous part of the urethra (Melament, 1972).

Mechanism of voiding in spinal cord injury patients has been hypothesised elsewhere (Perkash) and it does need further elaboration: Hutch (I967) established a reasonable basis for the physiology of micturition and he developed the concept of pre-voiding drop in pressure in the posterior urethra leading to the opening of the bladder neck. However, it is not clear how the micturition reflex sets in where progressive contraction of detrusor continues with relaxation of sphincter muscle. It is proposed that at the time of voiding, voluntary pull or tug through the striated voluntary sphincter muscle, the whole bladder neck and posterior urethra is pulled down, which leads to a pre-voiding drop in the pressure in the posterior urethra. This lets urine enter through the bladder neck leading to the stimulation of sensory receptors which are concentrated at and around the bladder neck and posterior urethra (Gosling and Dixon, 1974). This sets up a spinal micturition reflex with increasing detrusor contraction and simultaneous relaxation 

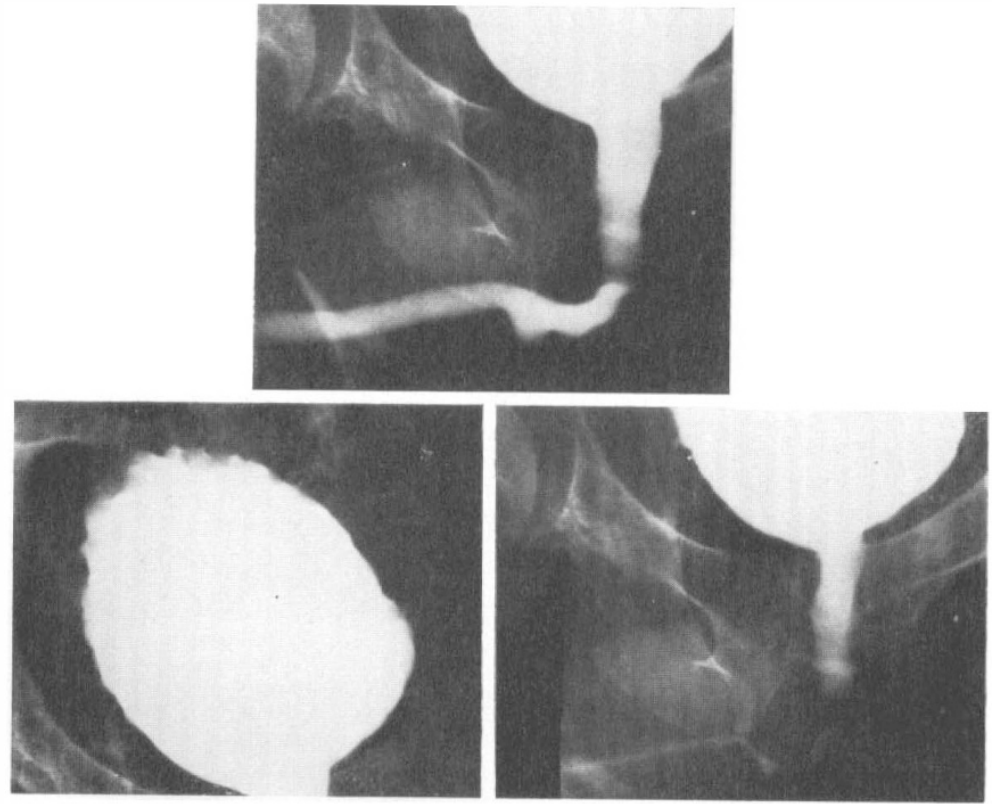

FIG. 4B

Voiding cyst. ureth. Three weeks post-sphincterotomy shows widely opened bladder neck and posterior urethra.
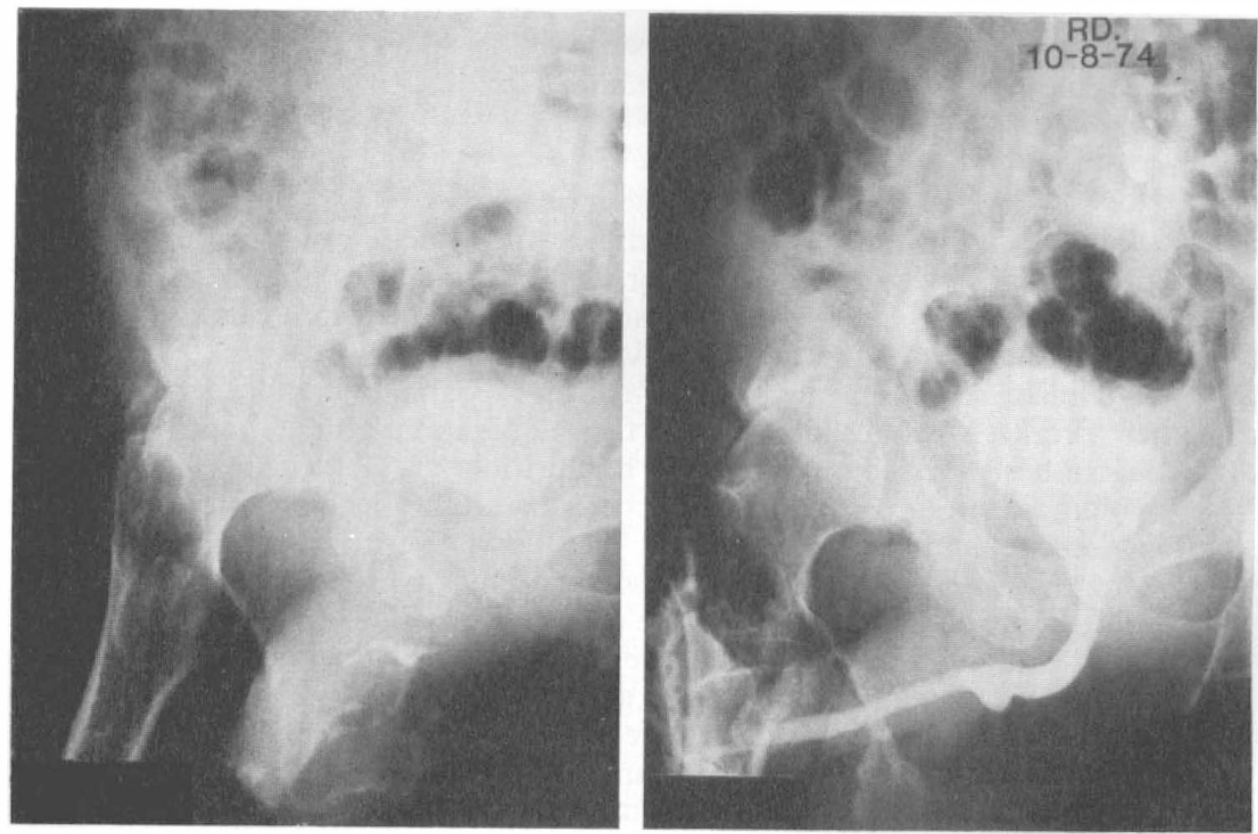

Fig. 4C

Voiding studies (both being spot films) about nine months post-sph. show adequate voiding which could be stopped and started with crede-valsalva. 

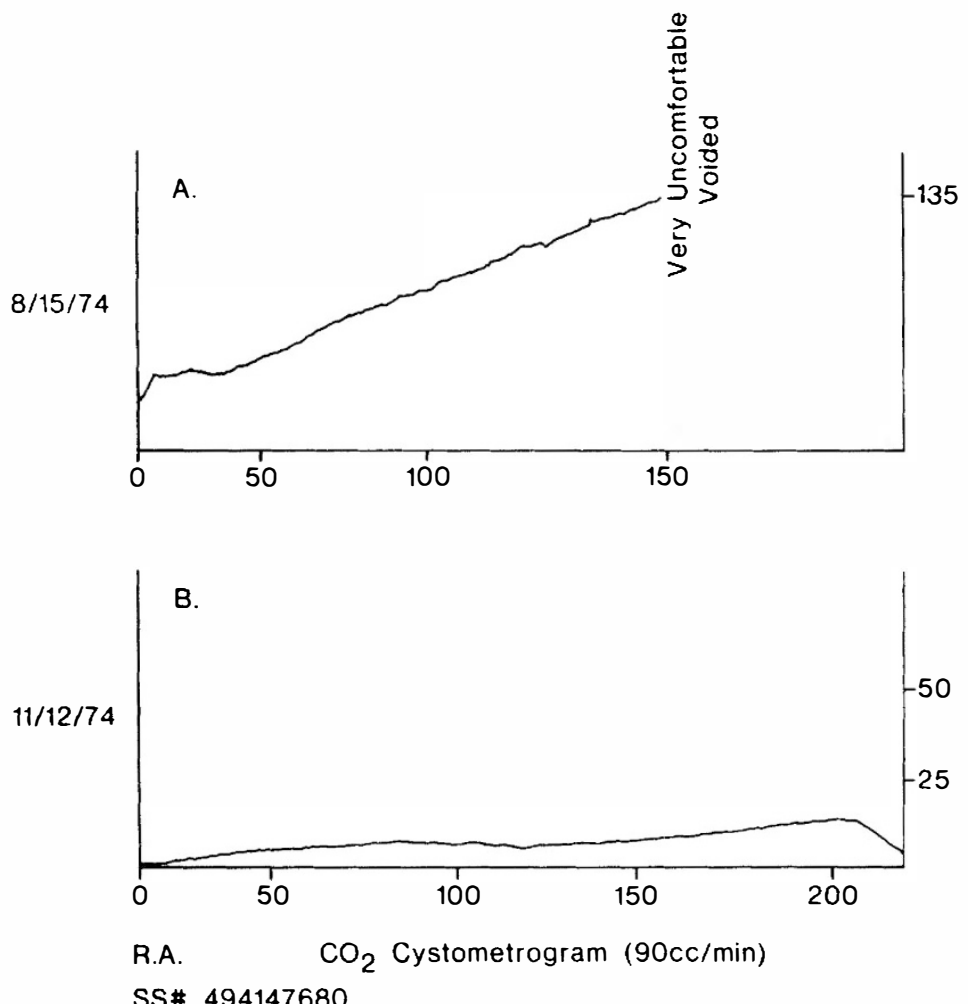

FIG. 5A

R. A., 50 years old, $\mathrm{T}_{12}-\mathrm{L}_{1}$ lesion presented $2 \frac{1}{2}$ years post-injury with difficult voiding. Pre-op. C.M.G. on I5 August 1974 shows high intravesical pressure; following sphincterotomy there was a pressure drop of over $100 \mathrm{~cm} . \mathrm{H}_{2} \mathrm{O}$.
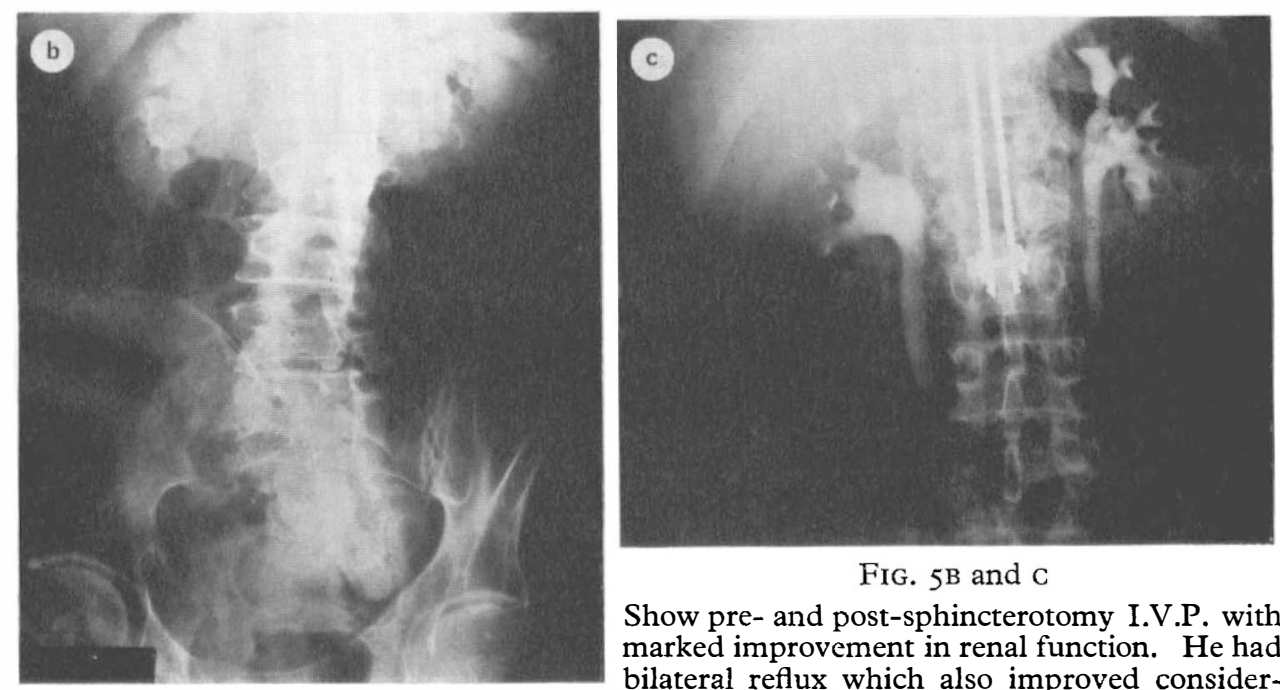

Fig. 5B and C

Show pre- and post-sphincterotomy I.V.P. with marked improvement in renal function. He had bilateral reflux which also improved considerably. 


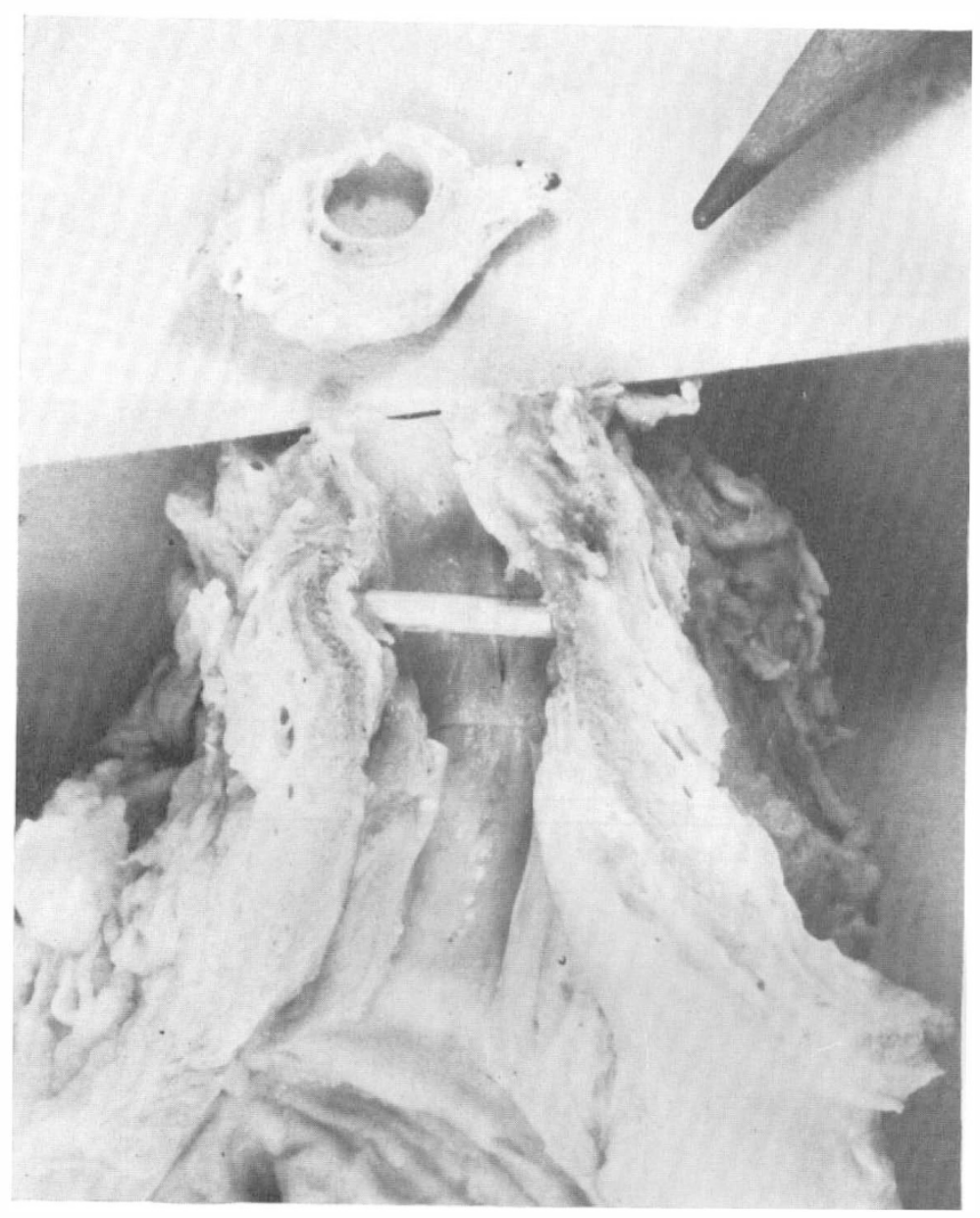

FIG. 6

A bladder neck preparation from a non-spinal cord injury cadaver shows laid-open urethra and posterior urethral anatomy.

of the sphincter musculature around the urethra. Spinal cord injury patients lack this mechanism of initiation of voiding. In patients with added complications of scarring of the bladder neck and overdistended or areflexic bladder, it is even more difficult for them to open bladder neck on attempted voiding to set up a micturition reflex. Such patients need to be recognised early to avoid prolonged intermittent catheterisation, overdistension of bladder and even vesico-urethral reflux. The ideal treatment for such patients is therefore an adequate sphincterotomy extending up to bladder neck. This would obviate the necessity for repeat transurethral surgery in such patients.

Initially, our results were unsatisfactory in two of our patients where inadequate bladder-neck incisions were made; however, later on with three incisions at three, 
nine and I2 o'clock results were satisfactory. Single incision at I2 o'clock or even adequate loop resection may not be easily accomplished as the thickness of posterior urethral musculature markedly diminishes at I2 o'clock in its distal part as is shown in Figure 6 . Chances of opening of sinuses and excessive bleeding are also increased. In the present series, three knife electrode incisions were made to avoid repeat surgery. Under the circumstances, even if one of them is not deep enough or if fibrosis can bridge one of the incisions, results would still be satisfactory as has been noticed in the present series.

Results of modified sphincterotomy have been equally satisfactory in both quadriplegics and low paraplegics. It therefore seems to be the operation of choice for all levels of spinal cord patients rather than first 'trying' transurethral resection and then in failures going for transurethral sphincterotomy. The role of sphincterotomy in the removal of long-term Foley indwelling catheters is also obvious from the present series. Such patients need a planned approach (Perkash, 1974) and a trial with intermittent catheterisation. However, in patients with severe autonomic dysreflexia, sphincterotomy is almost mandatory if the patients also have high residuals. In such patients, use of ganglion blockers or parasympatholytic drugs (Banthine) could lead to stoppage of reflex voiding. It was gratifying to see in two of our patients on long-term Foley indwelling catheters with severe autonomic dysreflexia, where, following sphincterotomy, not only catheters were removed but dysreflexic symptoms also improved considerably.

Management of vesico-ureteral reflux in paraplegic and quadriplegic patients needs careful consideration before a permanent indwelling catheter is left in, anti-reflux operation is done or an ileal loop diversion is contemplated. Since reflux almost disappeared in majority of our patients in three to five weeks post surgery and there was also significant improvement in the appearances of the upper tracts on I.V.P., adequate transurethral sphincterotomy seems to be the treatment of choice for the management of vesico-urethral reflux in spinal cord injury patients.

\section{SUMMARY}

Indications, technique and results of a modified approach to an extended sphincterotomy in spinal cord injury patients with voiding dysfunctions is presented. There were 32 patients who underwent surgery and were subjected to analysis for their dysfunctional bladder and bladder-neck problems. Overall satisfactory results were obtained in about 90 per cent patients following sphincterotomy. Early recognition of patients where intermittent catheterisation may not succeed is presented to intervene and establish an early catheter-free status in such patients. Foley indwelling catheter in ten patients, being worn from seven months to four years, where intermittent catheterisation had not succeeded elsewhere, were decatheterised following surgery. Excellent results were obtained in ten patients with vesico-urethral reflux; external sphincterotomy, therefore, seems to be the treatment of choice for complete spinal cord transection with vesico-ureteral reflux. An attempt has also been made to present physiology of micturition reflex in spinal cord injury patients.

\section{RÉSUMÉ}

Les indications, la technique et les résultats d'une sphinctérotomie modifiée dans les malades à lésiones de la moelle épinière avec malfonction de la vessie ont été présentés. 
Trente-deux malades avaient des interventions surgicaux et en suite étaient examinés pour analyse des déficits de vessie et des problèmes du col de la vessie. Des résultats favorables étaient obtenus par la sphinctérotomie dans environs 90 per cent des malades. Identification des malades qui ne profitaient pas de cathétrisation intermittente a été présentée avec recommendation d'intervention surgicale sans besoin de cathètre. Des cathètres permanents de Foley, en place pendant sept mois à quatre années dans des cas où la cathétrisation intermittente ne réussissait pas, avaient les cathètres éliminé à la suite d'intervention surgicale. Dix malades à reflux vésico-urétral avaient des résultats excellents. Donc la sphinctérotomie externe parait le traitement préféré en cas de transection médullaire spinale à reflux vésico-urétral. On a essayé également de présenter la physiologie du reflexe de micturation dans les malades à lésions de la moelle épinière.

\section{ZUSAMMENFASSUNG}

Die Indikation, Technik und Ergebnisse einer modifizierten Sphinkter Operation in Patienten mit Rückenmarksverletzungen wurde berichtet. 32 Patienten wurden operiert und danach auf Blasenfunktion und Problemen am Blasenhals untersucht. Zufriedenstellende Resultate wurden in 90 pro zent der Patienten nach Spinkter Operation erzielt. Frühzeitiege Erkennung von Patienten wurde besprochen in Fällen, in denen der chirurgische Eingriff die Katheter Behandlung unnötig machte, nachdem periodische Katheterisation nicht erfolgreich war. In zehn Patienten, die Dauer-Katheters für mindestens sieben Monate und bis zu vier Jahren hatten, da periodische Behandlung nicht efolgreich war, führte die Operation zu einer Katheterfreien Existenz. Ausgezeichnete Erfolge wurden erzielt in zehn Patienten mit vesiko-urethralen Rückflu $\beta$. Externe Sphinkterotomie erscheint daher als die beste Behandlung von totaler Rückenmarks Transektion mit vesikourethralem Rückflu $\beta$.' Es wurde auch versucht die Physiologie des Mikturitions Reflexes in Patienten mit Rückenmarksverletzungen zu beschreiben.

\section{REFERENCES}

Ascoli, R. R. (1967): Radiołogical study of the vesical neck in paraplegia secondary to spinal cord injury. Paraplegia, 4, 235.

Bors, E., Comarr, A. E. \& Reingold, I. M. (I954). Striated muscle fibers of the vesical neck. Fournal of Urology, 75, 273.

Currie, R. J., Bilbisi, A. A., SChielder, J. C. \& Bunts, R. C. (I970). External sphincterotomy in paraplegics: Technique and results. Fournal of Urology, 103, 64.

EMmetT, J. L. \& DuNN, J. H. (I946), Transurethral resection in the surgical management of cord bladder. Surg. Gynec. Obstet. 83, 597.

Gosling, J. A. \& Dixon, J. S. (1974). Sensory nerves in the mammalian urinary tract. An evaluation using light and electron microscopy. F. Anat. 117, I33.

HuTCH, J. A. \& RAMBO, O. (I967). A new theory of the anatomy of the internal urinary sphincter and the physiology of micturition. III. Anatomy of the urethra. Fournal of Urology, 97, 696.

Melament, A. (1972). External sphincterotomy in neurogenic bladder dysfunction. Fournal of Urology, 108, 554.

O'FLYNN, J. D. (I972). External sphincterotomy for the relief of outlet obstruction in neurogenic bladder. Paraplegia, 10, 29.

PERKASH, I. (I974). Intermittent catheterization: The urologist's point of view. Fournal of Urology, III, 356.

Perkash, I. (1975). Intermittent catheterization and bladder rehabilitation in spinal cord injury patients. Fournal of Urology, II4, 233.

Perkash, I. (1976). An attempt to understand and treat voiding dysfunctions during rehabilitation of the bladder in spinal cord injury patients. Fournal of Urology, 11 5, 36 .

Ross, J. C., GibBon, N. \& Damanski, M. (1963). Further experiences with diversion of external sphincter in the paraplegic. Fournal of Urology, 89, 692.

Rossier, A. B. \& OTT, R. (1974). Urinary manometry in spinal cord injury: A follow up study. Value of cysto-sphincterometrography as an indication for sphincterotomy. British Fournal of Urology, 46, 439. 